\title{
Congenital Phrenic Nerve Palsy
}

National Cancer Institute

\section{Source}

National Cancer Institute. Congenital Phrenic Nerve Palsy. NCI Thesaurus. Code C101199.

Damage to the phrenic nerve that results in paralysis of the hemidiaphragm at birth. 